\title{
Development of a modelling tool to quantify faecal indicator levels in Cardiff Bay
}

\section{E. Harris, R. Falconer, D. Kay and C. Stapleton}

K. O'Hara, Environmental Advice Centre; and D. E. Evans, Arup Reference is made to the aeration system that has been installed in the barrage lagoon. This system is designed to mix the water body on a continuous basis and thus any bacteria are likely to be circulated through the water columns. Can the model be applied to a continuously mixed system and if so what would be the likely impact on faecal coliform concentrations in Cardiff Bay?

The barrage lagoon is essentially a large shallow freshwater eutrophic lake. It was forecast that algal blooms would be a feature of the impoundment, particularly during periods of hot, dry weather. Since the impoundment was flushed with seawater in 2000 , the algal turbidity would be expected to be higher after full closure of the barrage gates in 2001 than under flushed conditions. Solar radiation measurements could therefore vary from the conditions as shown in Fig. 8. What influence would this have on the model predictions?

\section{Author's reply}

The authors would like to thank Dr 0'Hara and Mr Evans for their interest in the paper. In the experience of the authors, the main purpose of an aeration system is to inject air into the water column to raise the dissolved oxygen and, in this case, maintain compliance with the Cardiff Bay Barrage Act 1993. Such aeration systems generally introduce insignificant additional momentum and have little or no significant impact on stratification. For a continuously mixed system, additional momentum or energy needs to be imparted into the water body via water jets or similar. If the water column is better mixed vertically, which can be modelled computationally, then the bacteria circulated through the water column will have an increased decay rate, as the bacteria throughout the water column will receive higher doses of bacterial irradiance which is the principal driver of inactivation.

Solar radiation measurements would be expected to vary from the conditions as shown in Fig. 8. The study was a snapshot to provide a limited amount of data where previously none existed. The measured radiation in the water column will vary from day-to-day as cloud cover and weather conditions vary and it may well be that algal blooms will serve to attenuate radiation incident at the water surface. However, the existence of blooms will itself be variable and to some extent dependent on the local weather conditions, water quality variables etc. The overriding factor in the amount of radiation penetrating to specific depths within the water column will be the irradiance at the water surface which we have found can vary over minutes, let alone over the longer timescale of an algal bloom, i.e. days to weeks. Varying solar radiation levels to account for different weather/seasonal conditions may be included in the model, and this will have an impact on the bacterial decay rates. Variation in algal turbidity can also be accommodated in the model by the attenuation coefficient, $K_{\mathrm{e}}$, in equation (7), which may be varied to take account of the variation in the degree of radiation penetrating the water column. 